\section{M18 EXPLORING THE EXPERIENCES OF YOUNG PEOPLE TRANSITIONING FROM PAEDIATRIC TO ADULT ASTHMA SERVICES: A QUALITATIVE STUDY}

${ }^{1} \mathrm{SJ}$ Rylance, ${ }^{1} \mathrm{M}$ Stewart, ${ }^{2} \mathrm{H}$ James, ${ }^{2} \mathrm{G}$ Jones. 'Liverpool School of Tropical Medicine, Liverpool, UK; ${ }^{2}$ Royal Liverpool and Broadgreen University Hospitals NHS Trust, Liverpool, UK

\subsection{6/thoraxjnl-2017-210983.440}

Introduction Adolescence presents many challenges for young people (YP) with chronic medical conditions, including the transition from paediatric to adult healthcare services. Improving provision for this age group is a National Health Service priority. Qualitative research is important to understand the priorities of YP and their families; data are available for YP with a variety of chronic childhood conditions, but lacking for asthmatics. This study explored the experiences of YP transitioning from paediatric to adult asthma services, identifying aspects of the process which could be improved.

Methods An interpretive, phenomenological approach was employed to identify emerging themes from individual semistructured interviews, conducted between May-June 2017. Patients aged 16-19 years were eligible if they had transitioned from paediatric services in the previous 2 years. Parents and specialist asthma nurses were also included, facilitating triangulation of data. Interviews were transcribed verbatim and a coding-tree developed, using an inductive approach, with organisation of key issues into theme and sub-themes, illustrated by representative quotes.

Results Interviews were conducted with 5 YP (mean age 17.4 years), 4 parents and 2 asthma nurses. Four key themes emerged, with consistency between YP and their parents; developing new relationships, emergency admissions, increasing responsibility and long-term management (see Table 1). YP described positive, personal relationships with the adult team, accessibility of hospital staff, and greater involvement in discussions and decision making. Families also appreciated the direct communication style, and new treatment options available in the adult-setting. Emergency care, particularly the unfamiliar A and E environment, was the major source of anxiety for all participants.

Conclusion Despite expressing negative initial feelings, YP and their families talked positively about their new asthma team and the transition process. Increased opportunities to meet the adult team, while still in the paediatric setting would be appreciated and help establish a trusting relationship. Families appreciated the continuity of care provided by the asthma nurses from both teams. Information regarding the transition process, as well as the adult healthcare setting, may also help alleviate concerns. Additionally, a red-flag system in A and E could highlight priority patients, and instil confidence that the provision of acute care would be appropriate and timely.
Abstract M18 Table 1 Themes expressed by patients and parents, relating to asthma transition

\begin{tabular}{|c|c|}
\hline \multirow{9}{*}{ 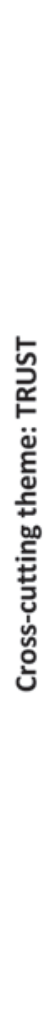 } & Key themes and sub-themes \\
\hline & Developing new relationships \\
\hline & $\begin{array}{l}\text { Knowing what to expect* } \\
\text { Meeting the new team; Meet and Greet, joint clinic* } \\
\text { Longstanding relationship with paediatric team } \\
\text { Adult team; direct communication, accessibility, } \\
\text { personal relationship }\end{array}$ \\
\hline & Emergency admissions \\
\hline & $\begin{array}{l}\text { Hospital appearance } \\
\text { In-between age } \\
\text { Shared environment with older patients; A\&E, ward } \\
\text { Loss of priority treatment* }\end{array}$ \\
\hline & Increasing responsibility \\
\hline & $\begin{array}{l}\text { Parents stepping back } \\
\text { Developing independence } \\
\text { Information and choice } \\
\text { Level of maturity }\end{array}$ \\
\hline & Long-term management \\
\hline & $\begin{array}{l}\text { Different treatment options } \\
\text { Monitoring } \\
\text { Asthma control } \\
\text { Clinic visits } \\
\text { Relationship with primary care }\end{array}$ \\
\hline
\end{tabular}

\section{M19 DIFFERENCES IN PATIENT AND PHYSICIAN VIEWPOINTS OF THE MANAGEMENT OF IDIOPATHIC PULMONARY FIBROSIS (IPF)}

${ }^{1} \mathrm{TM}$ Maher, ${ }^{2} \mathrm{JJ}$ Swigris, ${ }^{3} \mathrm{M}$ Kreuter, ${ }^{4} \mathrm{M}$ Wijsenbeek, ${ }^{5} \mathrm{~J}$ Axmann, ${ }^{6} \mathrm{~L}$ Ireland, ${ }^{7} \mathrm{SD}$ Nathan ${ }^{1}$ Interstitial Lung Disease Unit, Royal Brompton Hospital, London, UK; ${ }^{2}$ National Jewish Health, Denver, US; ${ }^{3}$ Pneumology and Respiratory Critical Care Medicine, Centre for Interstitial and Rare Lung Diseases, Thoraxklinik, Member of the German Centre for Lung Research, University of Heidelberg, Heidelberg, Germany; ${ }^{4}$ Department of Pulmonary Medicine, Erasmus Medical Centre, University Hospital Rotterdam, Rotterdam, Netherlands;

${ }^{5}$ F. Hoffman-La Roche, Basel, Switzerland; ${ }^{6}$ Hall and Partners, London, UK; ${ }^{7}$ Inova Fairfax Hospital, Falls Church, US

\subsection{6/thoraxjnl-2017-210983.441}

Introduction A majority of patients with IPF do not receive antifibrotic therapy with pirfenidone or nintedanib. We investigated viewpoints about IPF care and treatment amongst patients, and amongst physicians with a 'watch and wait' approach (WWP) or a proactive approach (PP). 
Methods Participants from Europe and Canada took part in an online survey. Responses were collected from patients with IPF, and from physicians responsible for initiation of IPF treatment who had consulted with $\geq 5$ patients with IPF within 3 months. A mixture of WWP (monitor for $\geq 4$ months post-diagnosis in $\geq 50 \%$ of patients before initiating antifibrotic) and PP (initiate antifibrotic $<4$ months post-diagnosis in majority of patients) were recruited.

Results 43 patients and 254 physicians were surveyed between September and October 2016. Only 56\% of patients felt that they received enough information at diagnosis: $58 \%$ were advised that IPF is progressive; 44\% discussed prognosis; and $49 \%$ were told about treatment options. Although the majority of patients (93\%) preferred to receive information from their physician, most patients sought additional information about IPF (86\%), treatment (81\%), and/or prognosis (76\%). Most patients $(86 \%)$ felt that the ability of antifibrotic treatments to slow IPF progression was more important than sideeffect profiles. Overall, $86 \%$ of patients who had received antifibrotic therapy felt confident in managing side effects. WWP were less likely to discuss IPF prognosis than PP, even when asked specifically by patients (Table). 62\% and 38\% of patients with 'mild' IPF were treated with an antifibrotic $<4$ months post-diagnosis by PP and WWP, respectively. WWP were more concerned about treatment side effects than PP (28\% vs 17\%, respectively); PP were more concerned about disease progression than WWP ( $83 \%$ vs $72 \%$, respectively).

Conclusions We identified a disparity between the information patients want at diagnosis and the information they receive from physicians. Furthermore, Results suggest that PP may be more confident with the benefit-risk profile of antifibrotic treatment than WWP. A belief in effective treatment options may aid conversation with patients regarding their IPF diagnosis, thereby enabling patients to make informed treatment decisions.

Abstract M19 Table 1 Differences between physicians regarding disease prognosis and treatment decisions

\begin{tabular}{lll}
\hline & $\begin{array}{l}\text { WWP } \\
\text { n=118 }\end{array}$ & n=136 \\
\hline Mention typical IPF prognosis at diagnosis & $47 \%$ & $59 \%$ \\
Will avoid discussing typical prognosis/life expectancy even when & $51 \%$ & $33 \%^{*}$ \\
patient asks & & \\
Comfortable discussing IPF prognosis & $21 \%$ & $34 \%^{*}$ \\
Strongly believe they can make a big difference in IPF patients' lives & $29 \%$ & $45 \%^{*}$ \\
post-diagnosis & & \\
Agree that antifibrotic therapies significantly slow the progression of & $36 \%$ & $51 \%{ }^{*}$ \\
IPF & & \\
Reasons for not treating patients with 'mild' IPF with an antifibrotic: & & \\
Patient is asymptomatic/has few symptoms & $66 \%$ & $36 \%^{*}$ \\
Patient has stable disease & $65 \%$ & $33 \%{ }^{*}$ \\
Patient has good lung function & $58 \%$ & $38 \%{ }^{*}$ \\
Patient has a good quality of life & $53 \%$ & $27 \%^{*}$ \\
Patient has IPF that is progressing slowly & $53 \%$ & $26 \%{ }^{*}$ \\
\hline
\end{tabular}

\section{M20 THINK WELL, FEEL WELL. ENABLING PARTICIPANTS TO DEVELOP HELPFUL COPING STRATEGIES IN THE MANAGEMENT OF SEVERE ASTHMA CHALLENGES}

H Hope, G McCumesky, R Niven. University Hospitals South Manchester, Manchester, UK

\subsection{6/thoraxjnl-2017-210983.442}

Introduction The psychological difficulties of those living with severe asthma are well documented, and can impact on disease severity and patient self-management. ${ }^{1}$

Objectives Our objective is to help patients achieve what is important to them (values), whilst living with severe asthma, and in doing so should feel more emotionally resilient. Resilience may enhance managing the challenges and demands of their illness, and promote better self-management.

Method A three hour workshop involving a number of exercises was designed to elicit daily struggles in relation to asthma, how that impacts on what is important to participants in life, and the emotional impact. Participants were then encouraged as a group to evaluate how they managed such struggles in relation to their values, and whether the coping strategy was helpful in them achieving their values, or less helpful, inadvertently causing more distress. The workshop was evaluated with an idiosyncratic rating scale administered before and after the workshop.

Results 17 participants completed two workshops. Post-workshop mean scores demonstrated improved coping with asthma and a greater range of coping strategies. However, post-workshop mean average scores also demonstrated greater awareness of difficulties, that asthma felt more overwhelming, and was a greater barrier to achieving valued activities in life, compared to pre-workshop mean scores. Subjective feedback included, patients feeling less alone, more hopeful, and that having a complex illness should not coincide with the experience of depression or anxiety as the norm.

Conclusion The Results suggest that when patients are enabled to evaluate how effective their coping strategies are in relation to their values, asthma and associated demands seem more manageable. However, the Results also suggest that patients were reminded of some of their challenges/difficulties, and have realised through workshop attendance that their current ways of coping may not be the most helpful, and could ultimately be contributing to their distress/disease management. Whilst this was not an anticipated finding, it highlights the importance of access to psychological assessment and treatment.

\section{REFERENCE}

1. Asthma UK. Treatments for Depression 2016. Available at: https://www.asthma. org.uk/advice/inhalers-medicines-treatments/other/depression/ [Accessed: 9.06.2017].

\section{M21 PATIENT STORIES: THE USE OF NOVEL ANTI-FIBROTICS, PIRFENIDONE AND NINTEDANIB, IN THE MANAGEMENT OF IDIOPATHIC PULMONARY FIBROSIS, IPF}

S Enston-Newall. Cardiff University, Cardiff, UK

10.1136/thoraxinl-2017-210983.443 
Background Pirfenidone and Nintedanib have been approved by NICE with the aim of attenuating progression and extending the prognosis for patients with IPF. There are no indications as to which should be used first line.

Aim Because neither Pirfenidone nor Nintedanib are intended to be curative, to investigate the effects of either drug on patients' quality of life, and to evaluate the patients' perspectives on their use in the management of IPF as a whole.

Method 15 patients were monitored over an 8 month period, and a patient story was compiled. Forced vital capacity was monitored as an indicator of the drugs clinical efficacy (a rate of decline that did not exceed $10 \%$ in 12 months). Then the patients' perspective on how treatment(s) affected their quality of life was evaluated; this included physical wellbeing, psychological wellbeing and any adversities associated with the drug (s). Weight was also monitored. Results were obtained through use of patient notes and verbal feedback during appointments. Results In no case did a patient's FVC decline greater than $10 \%$ in a 12 month period, suggesting Pirfenidone and Nintedanib were clinically effective in all cases. It was inconclusive what impact the drugs had on physical wellbeing, however both drugs improved patients' psychological wellbeing. Pirfenidone was associated with profound weight loss, anorexia, rash, constipation, nausea, dyspepsia, migraine, cough, hypersomnia and altered taste. All patients receiving Pirfenidone experienced at least one side effect. All eight patients

Abstract M21 Table 1 Treatment regimen of each patient involved in the study (this includes note of treatments that were discontinued).

\begin{tabular}{|c|c|c|c|c|c|}
\hline Reference & Gender & P irfenidone & Nintedanib & $\begin{array}{c}\text { Pulmonary } \\
\text { Rehabilitation }\end{array}$ & $\begin{array}{c}\text { Application for } \\
\text { Transplant }\end{array}$ \\
\hline A & $\therefore$ & $x$ & & & \\
\hline B & $\therefore$ & $x$ & $s$ & & \\
\hline C & $\therefore$ & & $x$ & $x$ & \\
\hline D & $\therefore$ & & $\checkmark$ & $s$ & \\
\hline $\mathrm{E}$ & $\therefore$ & $x$ & $\downarrow$ & , & \\
\hline F & $\therefore$ & $x$ & $\checkmark$ & $r$ & \\
\hline G & $\therefore$ & $x$ & & & \\
\hline $\mathrm{H}$ & ${ }^{2}$ & & $s$ & & \\
\hline I & $\circ$ & $x$ & $x$ & & \\
\hline J & 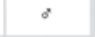 & & $x$ & & \\
\hline $\mathrm{K}$ & $\therefore$ & & 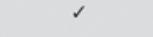 & s & Rejected \\
\hline L & $\therefore$ & & $s$ & & \\
\hline M & $\therefore$ & $x$ & $x$ & & \\
\hline $\mathrm{N}$ & 8 & $x$ & $x$ & s & Accepted \\
\hline 0 & $\circ$ & & $x$ & $x$ & Rejected \\
\hline & $\begin{array}{l}13 \text { males } \\
\text { and } 2 \\
\text { females } \\
\text { were } \\
\text { involved } \\
\text { in the } \\
\text { study }\end{array}$ & $\begin{array}{l}8 / 8 \text { patients } \\
\text { discontinued } \\
\text { treatment } \\
\text { with } \\
\text { Pirfenidone }\end{array}$ & $\begin{array}{l}6 / 13 \text { patients } \\
\text { discontinued } \\
\text { treatment } \\
\text { with } \\
\text { Nintedanib. } \\
7 \text { patients } \\
\text { were } \\
\text { to le rating } \\
\text { therapy } \\
\text { including } 1 \text { at } \\
\text { a reduced } \\
\text { dose }\end{array}$ & $\begin{array}{l}5 \text { patients } \\
\text { completed } \\
\text { Pulmonary } \\
\text { Rehabilitation. } \\
2 \text { had to } \\
\text { dis continue } \\
\text { formedical } \\
\text { reasons. }\end{array}$ & $\begin{array}{l}3 \text { patients } \\
\text { applied for } \\
\text { transplant. } 1 \text { is } \\
\text { on the waiting } \\
\text { list. } 1 \text { was } \\
\text { declined for } \\
\text { deteriorating } \\
\text { too quickly; the } \\
\text { other was } \\
\text { rejected for } \\
\text { being too well. }\end{array}$ \\
\hline \multicolumn{6}{|c|}{$J=$ receiving therapy } \\
\hline \multicolumn{6}{|c|}{$x=d$ is continued treatment } \\
\hline \multicolumn{6}{|c|}{$\downarrow=$ receiving a reduced dose } \\
\hline
\end{tabular}

discontinued treatment due to adversities. Nintedanib was associated with diarrhoea, impaired liver function, weight loss, fatigue, anorexia, arrhythmia and epistaxis. 6 out of 13 patients discontinued treatment due to adversities, however other patients reported no adversities whatsoever.

Conclusions Although both drugs were considered clinically effective, Nintedanib was tolerated in the majority without impairing quality of life, indicating the benefits have the potential to outweigh its risks. However because $100 \%$ of patients discontinued Pirfenidone due to adverse effects, the question regarding whether the benefits outweigh its adversities ideally needs to be re-addressed on a larger scale. This study is therefore in favour of Nintedanib being used first line should larger studies reflect a similar outcome.

\section{M22 DOES TELEPHONING PATIENTS BEFORE THE DIFFICULT- TO-TREAT ASTHMA CLINIC IMPROVE ATTENDANCE?}

S Oliveira, R Robinson, S Mault, B McDonough, H James, H Joplin, G Jones, J Blakey, H Burhan. Royal Liverpool and Broadgreen University Hospital Trust, Liverpool, UK

\subsection{6/thoraxjnl-2017-210983.444}

Aims To assess the use of telephone reminders in a difficultto-treat asthma service on:

1) clinic attendance rates

2) the prevalence of poor concordance

Background Non attendance at clinics leads to increased pressure on NHS resources and cost the NHS £3225 million in 2012 2013. Our trust has an opt-in appointment text message reminder service - despite which, the did-not-attend (DNA) rate at our tertiary asthma clinic was $\geq 20 \%$ in 2016 . It is known that up to $30 \%$ of patients attending tertiary asthma services have poor adherence with their asthma medication. ${ }^{1}$ We were interested in establishing whether directly telephoning patients prior to review would allow us to impact DNA rate and simultaneously identify non-concordant individuals that might be redirected to specialist pharmacy input prior to clinical review.

Methods During a 3 month period [Feb-Apr 2017] we telephoned patients $\geq 1$ week prior to their scheduled appointment - in total 3 attempts were made to contact an individual. During successful contacts express permission was sought to access electronic prescription fulfilment data.

Results Successful contact was made with 53.4\% [66/126] patients - 41 did not answer, 19 had no valid contact details. The majority of those contacted [54/66] agreed to an adherence check but only $n=37$ had been registered on the electronic prescription fulfilment system, of these 51\% [19/37] had an asthma medication pick-up rate $<80 \%$. Of those successfully contacted $n=64 / 66$ attended their appointment which compared favourably to the overall DNA rate during the same period in 2016 [3.0\% vs $17.5 \% ; \mathrm{p}=<0.05]$. Although we managed to perform a compliance check on less than a third of the total cohort [37/122], our telephone system allowed $\geq 1$ in 6 patients [19/122]to be directed to a dedicated specialist pharmacist led clinics (focussing on optimising concordance/education) thus creating additional capacity in our difficult-to-treat asthma service.

Conclusion Telephoning patients prior to clinic was associated with a substantial reduction in DNAs, and identified individuals that could benefit from a targeted intervention around concordance. The health economics of the intervention need further evaluation. 


\section{REFERENCE}

1. Robinson et al. Systematic assessment of difficult-to-treat asthma. ERJ 2003, September;22(3):478-83.

\section{M23 INTEGRATED RESPIRATORY CARE TRAINING FROM THE TRAINEE'S PERSPECTIVE: MIND THE GAP}

${ }^{1} \mathrm{~A}$ Jayadev, ${ }^{2} \mathrm{Z}$ Pond, ${ }^{3} \mathrm{~L}$ Preston, ${ }^{4} \mathrm{H}$ Ward. ${ }^{1}$ Homerton University Hospital, London, UK; ${ }^{2}$ University Hospital Southampton, Southampton, UK; ${ }^{3}$ British Thoracic Society, London, UK;

${ }^{4}$ New Cross Hospital , Wolverhampton, UK

\subsection{6/thoraxjn-2017-210983.445}

Introduction Postgraduate education needs to incorporate more training in community based settings for the '5 Year Forward View' to become a reality. A BTS members survey in 2013 found $62 \%$ of respondents agreed integrated respiratory physicians added value, and a subsequent report identified that embedding integrated care into training would be key. ${ }^{1,2}$ We surveyed the views of respiratory registrars to understand the current national training opportunities available in integrated respiratory care.

Methods The BTS Models of Care committee designed and distributed a questionnaire to trainee members in May 2017.

Results 81 trainees responded (43\% male; $87 \%$ working full time). The sample was representative with responses from all but one region. $80 \%$ of trainees participating were $\geq \mathrm{ST} 5$. $60 \%$ had not received any integrated respiratory care training and of those that had (figure 1);29\% described a single training episode (talk or clinic), 21\% attended a one day session, $42 \%$ described regular training episodes, e.g., MDT and 2\% had organised a placement themselves in an integrated care team for $\geq 1$ week. $90 \%$ of trainees felt it would be beneficial to have more integrated care experience. Key themes identified included a lack of clear definition of integrated care and an appreciation of the increasing relevance of this training.
Challenges identified include lack of training opportunities and incorporation into an already full curriculum.

Conclusions Despite 90\% of respondents wanting more experience and $77 \%$ considering, in part, some integrated respiratory work in their consultant job plan, only $40 \%$ had received any formal training of which $50 \%$ had only 1 day. This may be due in part to the 'poor definition' of integrated care which appears to be a persistent common theme. One of the future tasks of the BTS Models of Care Committee will be to provide guidance in developing and delivering programmes of training in Integrated care for Respiratory trainees.

\section{REFERENCES}

1. Roberts NJ et al. P34. what is integrated care and what is the value of an integrated respiratory specialist? BTS Abstracts 2013, Winter Meeting.

2. BTS Report. Role of the respiratory specialist in integrated care teams 2014 http://www.brit-thoracic.org.uk

\section{Idiopathic pulmonary fibrosis treatment update}

\section{M24 DO ANTIFIBROTICS IMPACT ON LUNG TRANSPLANTATION OUTCOMES IN IDIOPATHIC PULMONARY FIBROSIS?}

${ }^{1}$ YK Huong, ${ }^{2} \mathrm{~V}$ Dhunnoo, ${ }^{1} \mathrm{C}$ Leonard, ${ }^{1} \mathrm{R}$ Venkateswaran, ${ }^{1} \mathrm{~N}$ Chaudhuri. ${ }^{1}$ University Hospital of South Manchester, Manchester, UK; ${ }^{2}$ University of Manchester, Manchester, UK

10.1136/thoraxjnl-2017-210983.446

Introduction Antifibrotics slow progression of forced vital capacity (FVC) in patients with moderate Idiopathic Pulmonary Fibrosis (IPF) (FVC 50\%-80\%). ${ }^{1,2}$ Lung transplantation (LTx) is also a management option in a small cohort of patients who meet stringent eligibility criteria. With increased

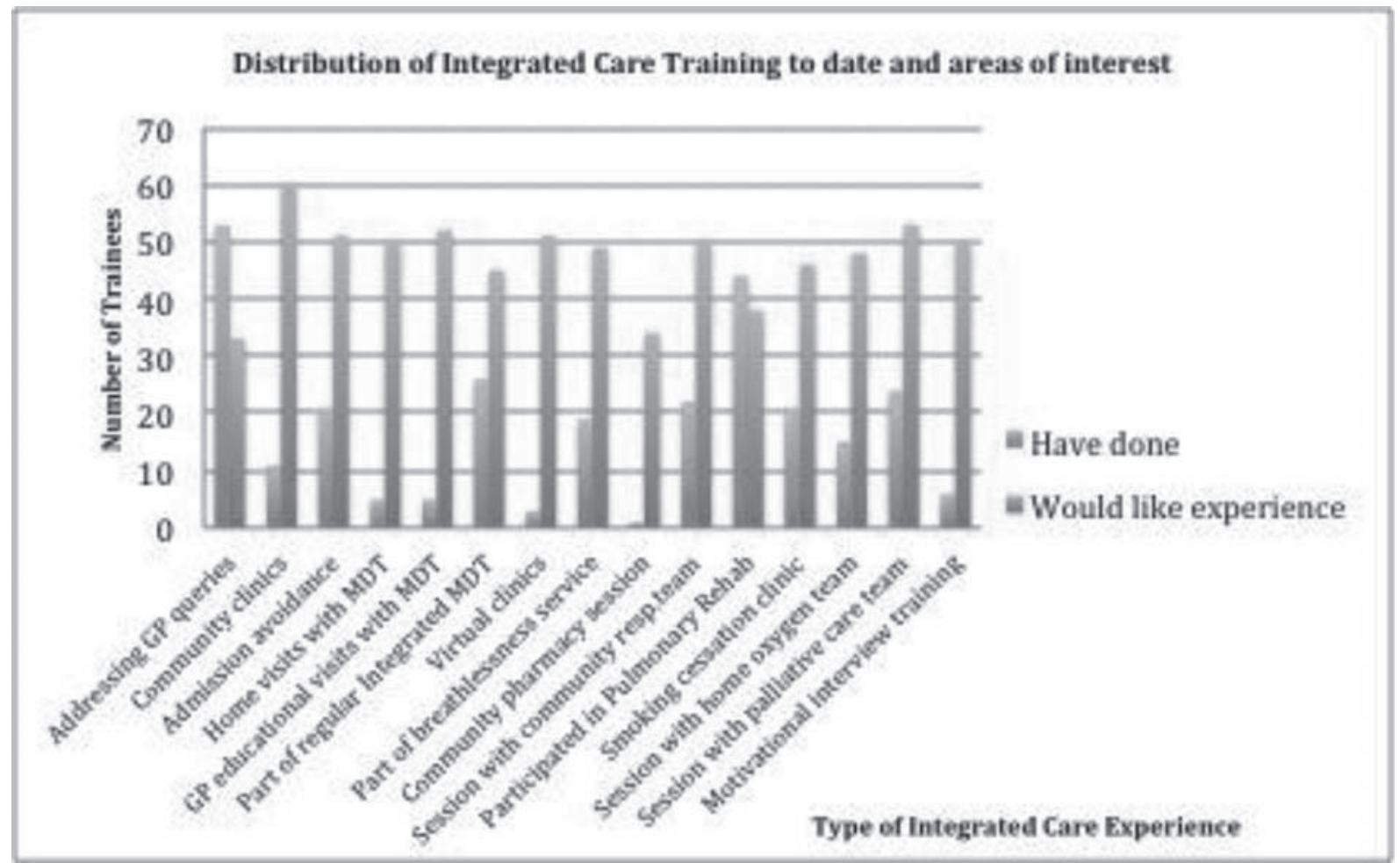

